\title{
A rapid alternative technique for obtaining silver-positive patterns in chromosomes
}

\author{
Karine Frehner Kavalco and Rubens Pazza \\ Universidade Federal de São Carlos, Departamento de Genética e Evolução, São Carlos, SP, Brazil.
}

\begin{abstract}
Silver nitrate chromosome staining to evidence nucleolar organizer regions (NORs) is a widely adopted methodology. The aim of the present work was to improve this technique, reducing the preparation time without decreasing the quality of the results. Microwave irradiation proved to be quite efficient and reliable for this purpose, as it allowed to identify Ag-NORs equivalent to those obtained by the conventional procedure and also to reduce the concentration of the employed reagents, as well as the precipitation of debris on the preparation.
\end{abstract}

Key words: silver staining, Ag-NOR, microwaves, chromosome banding.

Received: March 19, 2003; Accepted: December 4, 2003.

\section{Introduction}

The chromosomal localization of $45 \mathrm{~S}(18 \mathrm{~S}+5.8 \mathrm{~S}+$ $28 \mathrm{~S}$ ) and $5 \mathrm{~S}$ ribosomal genes can be accomplished by fluorescent in situ hybridization (FISH) with specific rDNA probes (Pinkel et al., 1986). However, the most commonly adopted method for detecting nucleolar organizer regions NORs - has been silver nitrate staining, because of its efficacy and easy performance (Goodpasture \& Bloom, 1975; Howell \& Black, 1980; Rufas et al., 1982).

It is assumed that silver nitrate attaches to nucleolar proteins and not directly to rDNA (Miller et al., 1976; Goessens, 1984; Hernández-Verdún, 1986), besides the necessity of transcriptional 45 rDNA activity during the preceding interphase (Howell, 1977; Hubbell, 1985; Jiménez et al., 1988). Nevertheless, it is also hypothesized that the uncondensed state of the chromatin could be enough to determine chromosome impregnation by silver nitrate, thus discarding the requirement for transcriptional pre-activity (Clavaguera et al., 1983; Medina et al., 1983; Sánchez-Pina et al., 1984). In addition, rDNA-free regions can also be evidenced by silver staining, probably due to the presence of proteins rich in acidic residues (Sumner, 1990; Sanchez et al., 1995; Dobigny et al., 2002).

The localization of NOR sites is an important tool in certain studies, such as those on evolution and cytotaxonomy (Galetti Jr., 1998), and those on gene expression and diagnosis of pathogenic tumors (Pich et al., 2000). In the latter, the mean number of Ag-NORs is used as a patho-

Send correspondence to K.F. Kavalco. Universidade Federal de São Carlos, Departamento de Genética e Evolução, Rodovia Washington Luís, km 235, C.P. 676, 13565-905 São Carlos, SP, Brazil. E-mail: kavalco@biociencia.org. logical marker for some malignant tumors. As an alternative to the standard procedures, it was suggested to utilize microwave irradiation for nucleolus localization in histological preparations, in order to fasten and improve the diagnosis (Medina et al., 1995; Li et al., 1995).

The objective of the present work was to test the viability of microwave utilization to detect Ag-NORs in conventional chromosome preparations, obtained by airdrying from a cell suspension.

\section{Material and Methods}

Chromosome preparations of Leporinus mormyrops (Pisces: Anostomidae) were obtained by cell suspension technique (Bertollo et al., 1978). Control slides were stained with silver nitrate, according to the conventional procedure described by Howell \& Black (1980).

Onto the test slides, two drops of $1 \%$ aqueous gelatin solution with $0.25 \%$ formic acid and four drops of silver nitrate at $25 \%$ were placed. The slides were covered with coverslips and incubated for five seconds in the presence of high-potency microwaves. After incubation, the coverslips were removed and the slides were washed under tap water, stained with 5\% Giemsa for $30 \mathrm{~s}$, and air-dried.

The slides were analyzed under an optical microscope, and the selected metaphases were captured by using the Media Cybernetics image analysis system with the Image Pro Plus software.

\section{Results and Discussion}

The species Leporinus mormyrops was chosen because it bears a single pair of Ag-NORs. The results ob- 


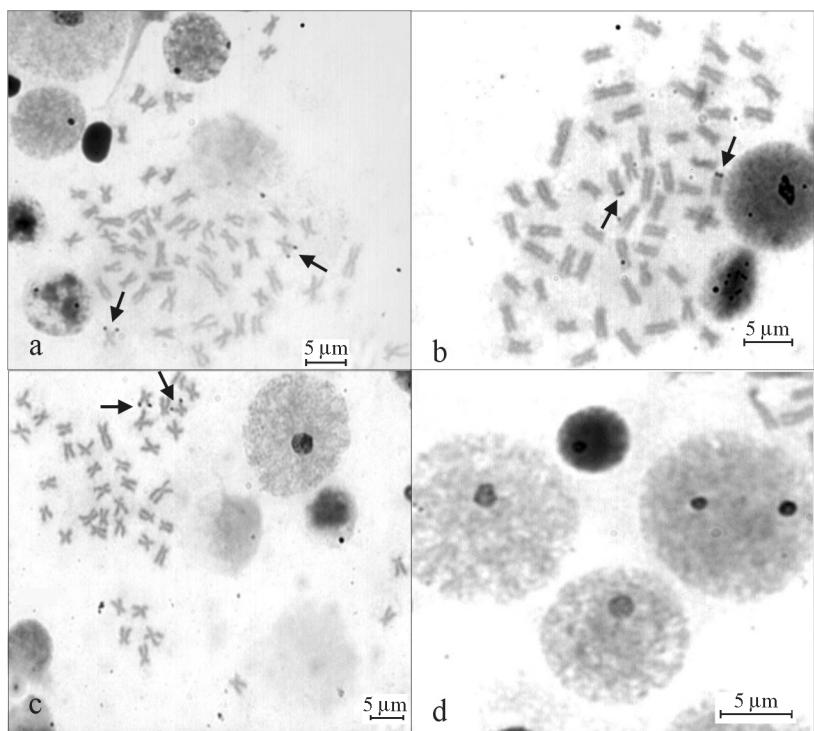

Figure 1 - Nucleolar organizer regions after silver nitrate staining using microwaves. (a-c) Metaphases. The arrows indicate the NORs sites. (d) Interphase nuclei.

tained are shown in Fig. 1 (a-c). It was observed that the quality of Ag-NORs revealed by the method described herein was similar to that obtained by the conventional method. Also, the nucleoli of interphase nuclei were quite evident (Fig. 1-d).

In the conventional method of Howell \& Black (1980), the silver nitrate impregnation has to be monitored in a drying chamber, until the adequate staining is obtained. At a temperature of $60{ }^{\circ} \mathrm{C}$, this time can vary from 3 to 5 min (in the drying chamber); higher temperatures usually lead to excessive drying, decreasing the preparation quality.

In the diagnosis of pathogenic tumors, the utilization of microwave irradiation shortened the time needed to evidence the nucleoli (Medina et al., 1995; Li et al., 1995) by up to one minute or close to it. Similarly, the exposure of the slides to microwaves drastically reduced the time needed for Ag-NOR detection, as they could be evidenced in approximately $5 \mathrm{~s}$.

The utilization of lower concentrations of both gelatin and silver nitrate is required to avoid the preparations to dry up, since the mechanism of action of microwaves in conventional ovens is based on the agitation of water particles, producing heat. Additional Giemsa staining improves the contrast between chromosomes and Ag-NORs, therefore being helpful for metaphase analysis.

Besides saving time, as compared to the usual silver nitrate staining technique, and eliminating the constant monitoring until an adequate coloration is reached, this procedure also allows to prepare several slides at the same time, as the microwave irradiation is homogeneously distributed within the oven. Another advantage of this method is the reduction of silver debris precipitation, common in the conventional procedure and responsible for difficulties in the analysis of the preparations.

\section{Acknowledgements}

The authors would like to thank Prof. Dr. Luiz Antonio Carlos Bertollo and Orlando Moreira-Filho for technical help and indispensable contributions to the work.

\section{References}

Bertollo LAC, Takahashi CS and Moreira-Filho O (1978) Cytotaxonomic considerations on Hoplias lacerdae (Pisces, Erythrinidae). Rev Bras Genet 1(2):103-120.

Clavaguera A, Querol E, Dolors C, Genesca J and Egozcue J (1983) Cytochemical studies on the nature of NOR (nucleolus organizer region) silver stainability. Cell Mol Biol 29:255-259.

Dobigny G, Ozouf-Costaz C, Bonillo C and Volobouev V (2002) "Ag-NORs" are not always true NORs: new evidence in mammals. Cytogenet Genome Res 98:75-77.

Galetti Jr PM (1998) Chromosome diversity in Neotropical fishes: NOR studies. Ital J Zool 65:53-56.

Goessens G (1984) Nucleolar structure. Int Rev Cytol $84: 107-158$.

Goodpasture C and Bloom SE (1975) Visualization of nucleolar organizer regions in mammalian chromosomes using silver staining. Chromosoma 53:37-50.

Hernández-Verdún D (1986) Structural organization of the nucleolus in mammalian cells. Meth Archiv Exp Pathol 12:26-62.

Howell WM (1977) Visualization of ribosomal gene activity: silver stain proteins associated with RNA transcribed from oocyte chromosomes. Chromosoma 62:361-367.

Howell WM and Black DA (1980) Controlled silver-staining of nucleolus organizer regions with a protective colloidal developer: a 1-step method. Experientia 36:1014-1015.

Hubbel HR (1985) Silver staining as an indicator of active ribosomal genes. Stain Technol 60:285-294.

Jiménez R, Burgos M and Diaz de la Guardia R (1988) A study of the silver staining significance in mitotic NORs. Heredity 60:125-127.

Li Q, Hacker GW, Danscher G, Sonnleitner-Wittauer U and Grimelius L (1995). Argyrophilic nucleolar organizer regions. A revised version of the Ag-NOR-staining technique. Histochem Cell Biol 104(2):145-150.

Medina FJ, Risueño MC, Sánchez-Pina MA and Fernandez-Gomez ME (1983) A study on nucleolar silver staining in plant cells. The role of argyrophilic proteins in nucleolar physiology. Chromosoma 88:149-155.

Medina FJ, Cerdido A and Marco R (1995) Microwave irradiation improvements in the silver staining of the nucleolar organizer (Ag-NOR) technique. Histochem. Cell Biol 103(6):403-413.

Miller DA, Dev VG, Tantravahi R and Miller OJ (1976) Suppression of human nucleolus organizer in mouse-human somatic hybrid cells. Exp Cell Res 101:235-243.

Pich A, Chiusa L and Margaria E (2000) Prognostic relevance of AgRONs in tumor pathology. Micron 31:133-141.

Pinkel D, Straume T and Gray JW (1986) Cytogenetic analysis using quantitative, high-sensitivity, fluorescence hybridization. Proc Natl Acad Sci 83:2934-2938. 
Rufas JS, Iturra P, De Souza W and Esponda P (1982) Simple silver staining procedure for the localization of nucleolus and nucleolar organizers under light and electron microscopy. Arch Biol 93:267-276.

Sanchez A, Jiménez R, Burgos M, Stitou S, Zurita F and Diaz de la Guardia R (1995) Cytogenetic peculiarities in the Alge- rian hedgehog: silver stains not only NORs but also heterochromatic blocks. Heredity 75:10-16.

Sánchez-Pina MA, Medina FJ, Fernández-Gómez ME and Risueño MC (1984) Ag-NOR proteins are present when transcription is impaired. Biol Cell 5:199-202.

Sumner AT (1990) Chromosome Banding. Unwin Hyman, London. 